DOI 10.37882/2223-2982.2021.06.30

\title{
ИМЕНА СОБСТВЕННЫЕ В ЗАГОЛОВКАХ ФРАНЦУЗСКОЙ ПРЕССЫ
}

\section{PROPER NAMES IN THE HEADLINES OF THE FRENCH PRESS}

\section{Matyushenko}

Summary: A news story presented by a journalist through a small "algorithm" of intriguing definitions displayed in the headline of newspaper and magazine articles allows you to interest the readership and acts as a motivational determinant for reading the material. The denotative function in the headlines of the press with proper names is performed by onyms. The specifics of headlines that include proper names in their composition is that this principle of presenting the material helps to attract a specific group of recipients who are interested in receiving certain information, for example, the name of a popular musician will become attractive to fans and music lovers, and the name of the ship will gather around readers whose associative series correlates with this object for professional or reminiscent reasons.

The research material, reflecting the specifics of the use of proper names in the text of the headlines of French periodicals, was journalistic articles of popular central publications, namely: Le Devoir, Le Figaro, Le Métro, Le Monde, Libération, L'Equipe, Les Échos, Libération, Nice-Matin, Le Huffington Post, Le Point, Le Nouvel Observateur for 2020 - 2021.

Keywords: proper names, onyms, press, headlines, mass media, newspaper, French publications.

\author{
Матюшенко Мария Сергеевна \\ Преподаватель, Всероссийская академия внешней \\ торговли Министерства экономического развития \\ Российской Федерации \\ tenvetrajulian@mail.ru
}

Аннотация: Новостная история, представленная журналистом посредством небольшого «алгоритма» интригующих дефиниций, отображающихся в заголовке газетных и журнальных статей, позволяет заинтересовать читательскую аудиторию и выступает в роли мотивационного детерминанта к прочтению материала. Денотативную функцию в заголовках прессы с именами собственными выполняют онимы. Специфика заголовков, включающих В свой состав имена собственные, заключается в том, что такой принцип подачи материала помогает привлекать конкретную группу реципиентов, которые заинтересованы в получении определённой информации, например, имя популярного музыканта станет привлекательным для фанатов и меломанов, а название корабля соберет вокруг себя читателей, чей ассоциативный ряд коррелирует с данным объектом по профессиональным или реминисцентным причинам.

В качестве исследуемого материала, отображающего специфику использования имен собственных в тексте заголовков французских периодических изданий, выступили публицистические статьи популярных центральных изданий, а именно: Le Devoir, Le Figaro, Le Métro, Le Monde, Libération, L'Equipe, Les Échos, Libération, Nice-Matin, Le Huffington Post, Le Point, Le Nouvel Observateur $3 a$ 2020 - 2021 годы.

Ключевые слова: имена собственные, онимы, пресса, заголовки, СМИ, газета, французские издания.

французской прессы. Данные лексические единицы выступают в роли культурного, лингвистического и/или информационного ориентиров в подсознании читателей, при этом они представлены в виде различных типов ментальных репрезентаций: «категорий, фреймов, скриптов, сценариев, образов, картин, гештальтов, концептов и т.д.» [4, с. 24].

Целью статьи является исследование имён собственных, используемых в заголовках французской прессы, как способа идентификации читательской аудиторией релевантного материала.

В данной статье выполнены следующие задачи:

1. найдены и проанализированы заголовки статей, в состав которых входят имена собственные;

2. определена роль имен собственных, включенных в текст заголовков газет и журналов;

3. дифференцированы имена собственные, используемые в прессе в номинативных целях.

В статье использованы такие методы, как контентанализ, контекстологический метод, метод сплошной выборки и систематизация полученного материала. 
В популярных изданиях наиболее важными функциями являются привлечение внимания и развлечение [26, р. 165]. Заголовки, в состав которых входят имена собственные, привлекают внимание читательской аудитории, так как содержание информации может быть сразу понято за счёт грамотно подобранных онимов, «заставляющих» реципиентов прочесть материал статьи.

Опираясь ан концепцию Л.Б. Зупаровой (2008), полагаем, что имена собственные могут фигурировать в заголовках французской прессы в трёх случаях:

1. Лицо принимало участие в написании текста или подборке материала (по нашему мнению, сюда целесообразно включать авторов статьи или очевидцев описываемых происшествий и/или ситуаций, а также интервьюированных лиц. По М.А. Дрога - «антропонимы» [1, с. 35]). Например, 'Euro 2021: Marine Le Pen appelle la FFF à «renoncer au choix de Youssoupha»' [11] Le Huffington Post, le 9 mars 2021 - «Евро-2021: Марин Ле Пен призывает FFF «отказаться от выбора Юссуфыл»» (перев. автора). Марин Ле Пен - французский политик, дидер политической партии «Национальный фронт». Или 'Israël-Gaza: Macron et Sissi travaillent à une médiation, avec la Jordanie' [15] Le Nouvel Observateur, le 17 mai 2021 - «Израиль-Газа: Макрон и Сиси работают над посредничеством с Иорданией» (перев. автора): Эммануэль Макрон и президент Египта Абдель Фаттах-ас-Сиси в обсуждали посредничество, направленное на обеспечение прекращения огня между Израилем и палестинцами.

2. Лицо или объект, которым посвящена статья или о которых в статье говорится, по М.А. Дрога - «антропонимы» [1, с. 35]. «Специалисты называют данные заголовки персоналиями» [2, с. 190]. Полагаем, в данную группу релевантно отнести:

(а) имена или фамилии, (по М.А. Дрога - «антропонимы» [1, с. 35]) кому посвящена статья, напримep, 'Nîmes Olympique: Rani Assaf veut déposer le bilan' [24] Le Nouvel Observateur, le 21 mai 2021. "Ним Олимпик' Рани Ассаф хочет подать заявление» (перев. автора). Либо имена и фамилии обозначенных лиц, о ком пишется материал, например, 'Macron annonce la création d'un statut de «mort pour le service de la République»' [6] Le Huffington Post, le 21 maі 2021. «Макрон объявляет о создании статута «смерть за службу Республике» - перев. автора. Или 'Justin Trudeau vilipendé par les médias anglophones' [29] Le Devoir, le 21 mai 2021 - «AHглоязычные СМИ критикуют Джастина Трюдо» (перев. автора).

(б) названия заболеваний (эпонимического и топонимического происхождений), например, 'Соvid-19 : Boulogne-Billancourt diffuse les données de santé d'une habitante' [9] Le Point, le mai 2021. «Covid-19: Булонь-Бийанкур распространяет данные о здоровье жителя» (перев. автора). Или 'Les grands laboratoires promettent 3,5 milliards de doses de vaccin contre la COVID-19 aux pays pauvres' [7] Le Devoir, le 21 mai 2021 - «Крупные лаборатории обещают бедным странам 3,5 миллиарда доз вакцины против COVID-19» (перев. автора).

(в) наименования географических объектов (по М.А. Дрога - «урбанонимы» [1, с. 35]), например, 'La Chine a-t-elle subtilisé la technologie de la 5 G au Canada ?' [16] Le Nouvel Observateur, le 21 mai 2021 «Китай украл технологию 5G у Канады?» (перев. автора). Также мы здесь видим использование в заголовке имени собственного интернет-технологии, а именно беспроводной системы связи пятого поколения - 5G, что позволяет «модернизировать» заголовок и привлечь внимание аудитории, интересующейся последними инновациями в сфере информационных систем. Или 'Iles Salomon : il découvre une centaine d'obus dans son jardin' [14] Le Point, le 21 mai 2021 - «Соломоновы острова: в их садах обнаружены сотни ракушек» (перев. автора). Соломоновы острова - архипелаг, расположенный в южной части Тихого океана.

(г) наименования астрономических объектов (по М.A. Дрога - «астронимы» [1, с. 35]), напримep, " Of Land and Bread : Ia politique israélienne en Cisjordanie dans le regard de Palestiniens' [21] Le Monde, le 27 mars 2021 - «О Земле и хлебе»: nолитика Израиля на Западном берегу глазами naлестинцев» (перев. автора). Или 'Mars 2020-Mars 2021: qu'est-ce qui a changé?' [22] Le Figaro, le 26 mars 2021 - «Марс 2020 - Марс 2021: что изменилось?» (перев. автора), Марс - планета, колонизируемая человечеством.

(д) названия праздников - геортонимы, например, 'Le Yachting Festival de Cannes se déroulera bien en septembre' [18] Nice-Matin, le 21 mai 2021 - «Каннский фестиваль-яхтинг успешно проведут в сентябре» (перев. автора) или 'Thierry Frémaux : «ll faut faire un grand Festival de Cannes !»' [8] Nice-Matin, le 20 mai 2021 - «Тьерри Фремо : «надо сделать больщой Каннский фестиваль!»» (перев. автора). Festival de Cannes («Каннский фестиваль») - ежегодный кинематографический фестиваль, проводимый во Франции (г. Канн).

(е) названия газет, журналов, медиагрупп или Интернет-контентов - гемеронимы, например, 'Dov Alfon, l'espion qui aimait « Libé «' [12] L'Equipe, le 15 octobre 2020 - «Дов Альфон (фамилия и имя), шпион, любивший « Libé «» (перев. автора). 'Libé' - сокращенное название французского критического издания Libération. Или 'Naspers/ Tencent : Mandarin pressé' [23] Les Échos, le 25 mars 2018 «Naspers / Tencent: мандарин в спешке» (перев. автора). 'Naspers' - Южно-Африканская медиагруппа, 'Tencent' - инвестиционная холдинговая компания в Китае. 
(ж) названия производств, организаций, компаний и концернов - хоронимы, например, 'TESLA prépare son arrivée en Inde' Le Figaro' [27], le 08 avril 2021 - «Tesla готовится к приезду в Индию» (перев. автора); 'Tesla s'agace de la bureaucratie allemande' [28] Le Figaro, le 08 avril 2021 - «Tesla раздражает немецкую бюрократию» (перев. автора). 'Tesla' - американская компания-производитель электромобилей - мировой лидер по поставке гибридов и электрокаров.

(з) названия партий, сообществ, объединений и пр., о которых идёт речь в тексте статьи, напримep, 'Le PLQ amorce un «virage vers le progrès» dans ses propositions économiques' [5] Le Devoir, le 21 mai 2021 - «PLQ в своих экономических предложениях начинает "сдвиг в сторону прогресса» " (перев. автора). 'PLQ' - Parti libéral du Québec - Либеральная партия Квебека.

(и) названия самолётов/кораблей/машин и прочей техники - порейонимы, и их одноименных производств, 'RER B : RATP et SNCF ont signé le contrat avec le consortium Bombardier-CAF' [25] Le Figaro avec AFP, le 05 février 2021 - «RER B: RATP u SNCF nodписали контракт с консорциумом BombardierCAF», Bombardier - это реактивный пассажирский самолёт. Или'Tourisme fluvial : CroisiEurope tente de se relancer' [10] Les Échos, le 20 juillet 2020 - «Речной туризм: CroisiEurope пытается возродиться», 'CroisiEurope' - флот речного туризма.

3. Следует выделить еще одну группу имён нарицательных, используемых в заголовках прессы - онимы, вызывающие определенные реминисценции (воспоминания) у читательской аудитории благодаря своей прецедентности [1, с. 34] или социокультурным когнициям: «заголовок является заголовком, содержащим текстовую реминисценцию» [3, с. 43], - подчёркивает О.В. Лисоченко (2007).

К данной группе также отнесём названия фильмов, песен или других объектов искусства - артионимы, наименования мессенджеров, социальных сетей и приложений. Подчеркнем, что прецедентность названий мобильных приложений и коммуникативных онлайн-платформ, как и объектов искусств, преимущественно, таких недолговечных, как современные фильмы или названия песен, в особенности, если они не культовые, обусловлена их ситуативностью и темпоральностью, например:

- фильм: 'Le film «Beans» sacré aux Prix Écrans canadiens' [20] Le Devoir, le 21 mai 2021 - «Фильм «Фасоль» коронован на церемонии вручения награды Canadian Screen Awards».

- мобильное приложение: Например, бесплатная система мгновенного обмена текстовыми сообщения 'ICQ', активно функционирующая с 1996 по 2006 гг., в настоящий момент предельно редко используется, так как практически изжила себя и подавлена более конкурентоспособными программами. Например: 'ICQ devient américain' [13] Le Monde, le 11 juin 1998 - «ICQ становится американской» - перев. автора. А коронавирусная инфекция нового Sars-Cov2 типа породила множество прецедентных имен собственных, используемых, в том числе, при именовании мобильных предложений. Например: 'L'appli StopCovid dans le collimateur du PNF' [19] Libération, le 21 mai 2021 - «Приложение StopCovid в прицелах PNF (Le parquet national financier - французское судебное учреждение, a StopCovid - это специальное программное обеспечение для отслеживания случаев заболевания Covid-19) - перев. автора) или 'Le lien entre Uber et un chauffeur requalifié en contrat de travail' [17] Le Point, le 21 mai 2021 - «Отношения между Uber и водителем трансформированы в трудовой договор» (перев. автора). 'Uber' - это американское мобильное приложение, позволяющее вызвать такси и отслеживать его траекторию движения.

\section{Выводы:}

Случайный выбор новостных сюжетов с именами собственными в заголовках иллюстрирует языковую картину мира французов и их гештальты.

Среди наиболее популярных имен собственных - это онимы. Данью современности являются инноватизационные процессы в сфере IT-технологий и автомобилестроения, что находит своё отражение при именовании статей, а также предельно актуальна тема распространения и борьбы с коронавирусной инфекцией нового типа - Sars-Cov2 - данный феномен породил множество заголовков, которые комбинируют в себе наименование заболевания коронавирусной инфекции и урбанистические онимы (с целью конкретизации географической локации инфекции, что чрезмерно актуально для всех людей планеты, так как от этого зависят меры профилактики и борьбы с мировой пандемией, экономические и туристические взаимоотношения стран, открытие/закрытие межгосударственных границ и пр.).

В тройку лидеров имён собственных, активно включаемых в заголовки французских СМИ, входят антропонимы (фамилии или имена с фамилиями политических, экономических, религиозных, спортивных, медицинских и др. деятелей разных стран). 


\section{ЛИТЕРАТУРА}

1. Дрога, М.А. Имя собственное на газетной полосе (на материале составных наименований русского языка) / М.А. Дрога // МИРС. 2014. №4. - С. 34 - 38.

2. Зупарова, Л.Б. Аналитико-синтетическая переработка информации: учебник для студентов высших учебных заведений, обучающихся по специальности 052700 - Библиотечно-информационная деятельность / Л.Б. Зупарова, Т.А. Зайцева. - Москва: Фаир, 2008. - 399 с.

3. Лисоченко, 0.В. Риторика для журналистов: прецедентность в языке и в речи: учебное пособие для студентов, обучающихся по направлению 031000 и специальностям 031001 «Филология» и 030601 «Журналистика» / О.В. Лисоченко; отв. ред. Л.В. Поповская (Лисоченко). - Ростов-на-Дону: Феникс, 2007. - 318 с.

4. Шнякина, Н.Ю. Опыт моделирования событийного концепта (на материале вербализованной ситуации ольфакторной перцепции) [Текст]: монография / Н.Ю. Шнякина. - 2-е издание, стереотипное. - Москва: ФЛИНТА, 2018. - 182 с.

5. Bergeron, P. Le PLQ amorce un «virage vers le progrès» dans ses propositions économiques. Le Devoir, le 21 mai 2021. URL: https://www.ledevoir.com/politique/ quebec/603572/le-plq-amorce-un-virage-vert-dans-ses-propositions-economiques. Date: 21.05.2021.

6. Berthelier A., Hennequin L. Macron annonce la création d'un statut de «mort pour le service de la République» Le Huffington Post. Le 21 mai 2021 . URL: https:// www.huffingtonpost.fr/entry/emmanuel-macron-annonce-la-creation-dun-statut-de-mort-pour-le-service-de-la-republique_fr_60a75ffce4b0d56a83e819b7. Date: 21.05.2021.

7. Branchereau, G. Les grands laboratoires promettent 3,5 milliards de doses de vaccin contre la COVID-19 aux pays pauvres. Le Devoir, le 21 mai 2021. URL: https:// www.ledevoir.com/monde/603440/les-grands-laboratoires-promettent-3-5-milliards-de-doses-de-vaccin-contre-la-covid-19-aux-pays-pauvres. Date: 21.05.2021.

8. Carini, A. Thierry Frémaux : «ll faut faire un grand Festival de Cannes !» Nice-Matin, le 20 mai 2021. URL: https://www.nicematin.com/people/thierry-fremaux-ilfaut-faire-un-grand-festival-de-cannes-688602. Date: 21.05.2021.

9. Covid-19: Boulogne-Billancourt diffuse les données de santé d'une habitante. Le Point. le 21 mai 2021. URL: https://www.lepoint.fr/societe/covid-19-boulognebillancourt-diffuse-les-donnees-de-sante-d-une-habitante-21-05-2021-2427555_23.php. Date: 21.05.2021.

10. Donas, C. Tourisme fluvial : CroisiEurope tente de se relancer. Les Échos, le 20 juillet 2020. URL: https://www.lesechos.fr/pme-regions/grand-est/tourisme-fluvialcroisieurope-tente-de-se-relancer-1225011. Date: 21.05.2021.

11. Euro 2021: Marine Le Pen appelle la FFF à «renoncer au choix de Youssoupha» Le Huffington Post avec AFP, le 9 mars 2021. URL: https://www.huffingtonpost.fr/ entry/euro-2021-marine-le-pen-appelle-la-fff-a-renoncer-au-choix-de-youssoupha_fr_60a8150ae4b09604b5225305. Date: 22.05.2021.

12. Gasquet, P. Dov Alfon, I'espion qui aimait « Libé ». L'Equipe. Le 15 octobre 2020. URL: https://www.lesechos.fr/weekend/business-story/dov-alfon-lancien-espionbombarde-a-libe-1256046. Date: 21.05.2021.

13. ICQ devient américain. Le Monde, le 11 juin 1998. URL: https://www.lemonde.fr/archives/article/1998/06/11/icq-devient-americain_3675365_1819218.html. Date: 21.05 .2021$.

14. Iles Salomon : il découvre une centaine d'obus dans son jardin. Le Point, le 21 mai 2021. URL: https://www.lepoint.fr/monde/iles-salomon-il-decouvre-unecentaine-d-obus-dans-son-jardin-21-05-2021-2427571_24.php. Date: 21.05.2021.

15. Israël-Gaza: Macron et Sissi travaillent à une médiation, avec la Jordanie Le Nouvel Observateur, le 17 mai 2021. URL: https://www.nouvelobs.com/ politique/20210517.AFP8668/israel-gaza-macron-et-sissi-travaillent-a-une-mediation-avec-la-jordanie.html. Date: 22.05.2021.

16. Jauvert, V. La Chine a-t-elle subtilisé la technologie de la $5 \mathrm{G}$ au Canada ? Le Nouvel Observateur. Le 21 mai 2021. URL: https://www.nouvelobs.com/affairessecretes/20210521.0BS44284/la-chine-a-t-elle-subtilise-la-technologie-de-la-5g-au-canada.html. Date: 21.05.2021.

17. Le lien entre Uber et un chauffeur requalifié en contrat de travail. Le Point, le 21 mai 2021. URL: https://www.lepoint.fr/justice/le-lien-entre-uber-et-unchauffeur-requalifie-en-contrat-de-travail-21-05-2021-2427556_2386.php/ Date: 21.05.2021.

18. Le Yachting Festival de Cannes se déroulera bien en septembre. Nice-Matin, le21 mai 2021. URL: https://www.nicematin.com/economie/le-yachting-festival-decannes-se-deroulera-bien-en-septembre-689162. Date: 21.05.2021.

19. Lecadre, L. L’appli StopCovid dans le collimateur du PNF. Libération. Le 21 mai 2021. URL: https://www.liberation.fr/economie/lappli-stopcovid-dans-lecollimateur-du-pnf-20210521_nrau7csmsrgzlfd7uxltffk55a/. Date: 21.05.2021.

20. Lévesque, F. Le film «Beans» sacré aux Prix Écrans canadiens. Le Devoir, le 21 mai 2021. URL: https://www.ledevoir.com/culture/cinema/603320/prix-ecranscanadiens-le-film-beans-sacre-aux-prix-ecrans-canadiens. Date: 21.05.2021.

21. Mandelbaum, J. « Of Land and Bread » : la politique israélienne en Cisjordanie dans le regard de Palestiniens.' Le Monde, le 27 mars 2021. URL: https://www. lemonde.fr/culture/article/2021/03/27/of-land-and-bread-la-politique-israelienne-en-cisjordanie-dans-le-regard-de-palestiniens_6074654_3246.html. Date: 21.05.2021.

22. Mars 2020-Mars 2021: qu'est-ce qui a changé? Le Figaro, le 26 mars 2021. URL: https://video.lefigaro.fr/figaro/video/mars-2020-mars-2021-quest-ce-qui-achange/. Date: 21.05 .2021$.

23. Naspers/Tencent : Mandarin pressé. Les Échos. Le 25 mars 2018. URL: https://www.lesechos.fr/2018/03/nasperstencent-mandarin-presse-987421. Date: 21.05.2021.

24. Olivès-Berthet, C. Nîmes Olympique : Rani Assaf veut déposer le bilan. Le Nouvel Observateur. Le 21 mai 2021. URL: https://www.lequipe.fr/Football/Actualites/ Nimes-olympique-rani-assaf-veut-deposer-le-bilan/1254423 . Date: 21.05.2021.

25. RER B : RATP et SNCF ont signé le contrat avec le consortium Bombardier-CAF. Le Figaro avec AFP, le 05 février 2021. URL: https://www.lefigaro.fr/societes/rer-bratp-et-sncf-ont-signe-le-contrat-avec-le-consortium-bombardier-caf-20210205. Date: 21.05.2021. 
26. Shchedrina P. Functions of proper names in headlines of the British newspapers / P. Shchedrina // Актуальные проблемы журналистики: сборник трудов молодых ученых. Томск, 2014. Вып. 9. С. 164-165.

27. TESLA prépare son arrivée en Inde. Agence 0ption Finance. Le Figaro, le 08 avril 2021. URL: https://bourse.lefigaro.fr/actu-conseils/tesla-prepare-son-arrivee-eninde-20210408. Date: 21.05.2021.

28. Tesla s'agace de la bureaucratie allemande. Le Figaro avec AFP, le 08 avril 2021. URL: https://www.lefigaro.fr/flash-eco/tesla-s-agace-de-la-bureaucratieallemande-20210408. Date: 21.05.2021.

29. Vastel, M. Justin Trudeau vilipendé par les médias anglophones. Le Devoir, le 21 mai 2021. URL: https://www.ledevoir.com/politique/canada/603404/projet-deloi-96-justin-trudeau-vilipende-par-les-medias-anglophones. Date: 21.05.2021.

(c) Матюшенко Мария Сергеевна (tenvetrajulian@mail.ru).

Журнал «Современная наука: актуальные проблемы теории и практики»

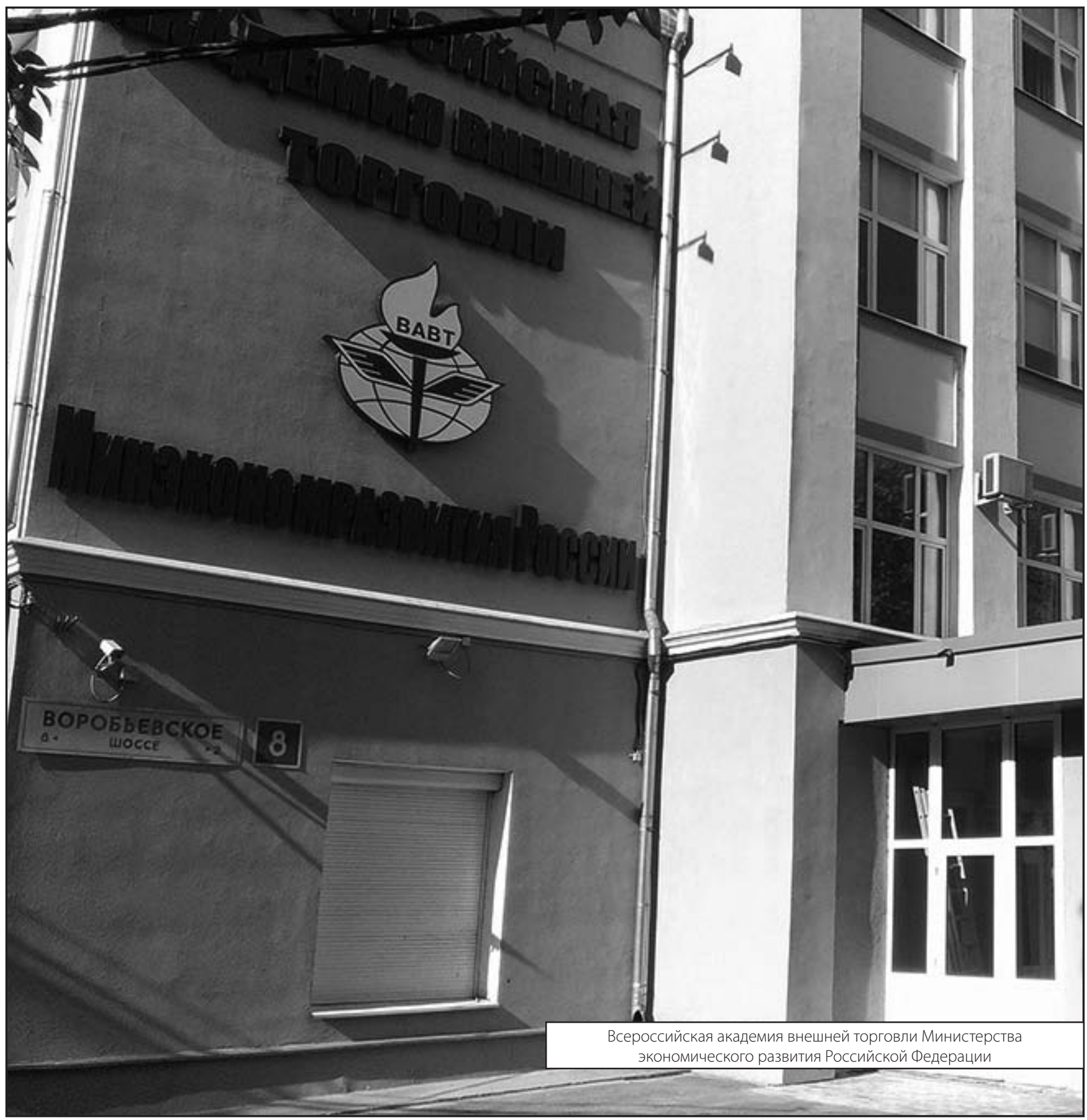

